\title{
Caracterização físico-química do leite fermentado por Lactobacillus helveticus adicionado de extrato de hibisco durante a estocagem
}

Physicochemical characterization of milk fermented by Lactobacillus helveticus added with hibiscus extract during storage

Caracterización fisicoquímica de la leche fermentada por Lactobacillus helveticus añadido con extracto de hibisco durante el almacenamiento

\section{Resumo}

Este trabalho propôs desenvolver um leite fermentado por Lactobacillus helveticus (LH) ou associada com cultura de Streptococcus thermophilus (LHST) adicionado de extrato de hibisco e avaliar a atividade antioxidante e evolução do crescimento das culturas láticas durante a estocagem sob refrigeração a $4 \pm 1^{\circ} \mathrm{C}$. O leite fermentado recebeu extrato de hibisco na forma livre (LHExL e LHSTExL) ou encapsulado com PVP e Tween 80 (LHExE e LHSTExE). Avaliou-se a atividade antioxidante (DPPH e FRAP) nos tempos de 1, 15 e 30 dias. Os resultados demonstraram que o teor de acidez titulável foi inferior após a fermentação. A viabilidade das bactérias láticas foi satisfatória, as quais atenderam os requisitos legais e mantiveram estáveis até 30 dias de estocagem para ambas as caldas do leite fermentado (LH e LHST). A atividade antioxidante frente ao radical DPPH foi superior a $80 \%$, porém não apresentou resultados conclusivos relativos à interação das culturas láticas e das diferentes formas de aplicação do extrato de hibisco. Porém, o LH apresentou maior atividade antioxidante pelo método FRAP quando associado ao extrato de hibisco encapsulado no tempo inicial. Esta análise permitiu observar que a associação do extrato de hibisco independente da forma veiculada ao leite fermentado aumentou a atividade antioxidante pelo método de FRAP e este manteve estável ao longo do tempo de estocagem. Portanto, o estudo permitiu concluir que o leite fermentado associado ao extrato de hibisco contribuiu com o aumento da atividade antioxidante e manteve estável ao longo do tempo de estocagem.

Palavras-chave: DPPH; FRAP; Composição proximal; S. thermophilus.

\begin{abstract}
This work proposed to develop a milk fermented by Lactobacillus helveticus (LH) or associated with a culture of Streptococcus thermophilus (LHST) added with hibiscus extract and to evaluate the antioxidant activity and growth evolution of lactic cultures during storage under refrigeration at $4 \pm 1^{\circ} \mathrm{C}$. Fermented milk received free form hibiscus extract (LHExL and LHSTExL) or encapsulated with PVP and Tween 80 (LHExE and LHSTexE). Antioxidant activity (DPPH and FRAP) was evaluated at 1, 15 and 30 days. The results showed that the titratable acidity content was lower after fermentation. The viability of the lactic acid bacteria was satisfactory, which met the legal requirements and remained stable up to 30 days of storage for both fermented milk (LH and LHST). The antioxidant activity against the DPPH radical was greater than $80 \%$, but it did not show conclusive results regarding the interaction of lactic cultures and the different forms of application of the hibiscus extract. However, LH showed greater antioxidant activity by the FRAP method when associated with hibiscus extract encapsulated in the initial time. This analysis allowed to observe
\end{abstract}


that the association of hibiscus extract regardless of the form conveyed to fermented milk increased the antioxidant activity by the FRAP method and this remained stable over the storage time. Therefore, the study allowed to conclude that the fermented milk associated with the hibiscus extract contributed to the increase in antioxidant activity and remained stable over the storage time.

Keywords: DPPH; FRAP; Proximal Composition; S. thermophilus.

\section{Resumen}

Este trabajo propuso desarrollar una leche fermentada por Lactobacillus helveticus (LH) o asociada a un cultivo de Streptococcus thermophilus (LHST) agregado con extracto de hibisco y evaluar la actividad antioxidante y evolución del crecimiento de cultivos lácticos durante el almacenamiento en refrigeración a $4 \pm 1^{\circ} \mathrm{C}$. La leche fermentada recibió extracto de hibisco en forma libre (LHExL y LHSTexL) o encapsulada con PVP y Tween 80 (LHExE y LHSTexE). Se evaluó la actividad antioxidante (DPPH y FRAP) en tiempos de 1, 15 y 30 días. Los resultados mostraron que el contenido de acidez titulable fue menor después de la fermentación. La viabilidad de las bacterias del ácido láctico fue satisfactoria, que cumplió con los requisitos legales y se mantuvo estable durante los 30 días de almacenamiento de ambos os leche fermentada (LH y LHST). La actividad antioxidante frente al radical DPPH fue superior al $80 \%$, pero no arrojó resultados concluyentes en cuanto a la interacción de cultivos lácticos y las diferentes formas de aplicación del extracto de hibisco. Sin embargo, la LH mostró una mayor actividad antioxidante por el método FRAP cuando se asoció con el extracto de hibisco encapsulado en el tiempo inicial. Este análisis nos permitió observar que la asociación de extracto de hibisco independientemente de la forma transportada a la leche fermentada aumentó la actividad antioxidante por el método FRAP y esta se mantuvo estable durante el tiempo de almacenamiento. Por lo tanto, el estudio nos permitió concluir que la leche fermentada asociada con el extracto de hibisco contribuyó al aumento de la actividad antioxidante y se mantuvo estable durante el tiempo de almacenamiento.

Palabras clave: DPPH; FRAP; Composición Proximal; S. thermophilus.

\section{Introdução}

O consumo de alimentos lácteos funcionais expandiu-se rapidamente pela sua qualidade nutricional e pelas proteínas de elevado valor biológico. Dentre esses produtos lácteos, destaca-se o leite fermentado, sendo um dos mais populares do mundo (Borgonovi, 2018; Capitani et al., 2014). Uma característica intrínseca do leite fermentado é a fermentação por diferentes bactérias ácidos lácteas que possuem sistemas proteolíticos que contribuem para o bom desenvolvimento no leite e na liberação de peptídeos potencialmente bioativos (Sah et al., 2014). Estes podem ser fermentados pelas bactérias ácido lácticas dos gêneros Lactococcus, Leuconostoc, Pediococcus, Streptococcus e Lactobacillus. Outras espécies bacterianas, como as dos gêneros Bifidobacterium e Enterococcus, estão sendo aplicadas no processo de fabricação de leites fermentados devido aos benefícios à saúde dos consumidores e a contribuição para novos perfis de sabor (Tamime, 2006).

Os Lactobacillus helveticus são de grande interesse tecnológico que é amplamente utilizada em estudos de laticínios devido ao seu rápido crescimento no leite e sua capacidade de crescer sob estresse ácido. O leite fermentado por cepas de $L$. helveticus apresenta a capacidade de liberar compostos bioativos capazes de exercer importantes propriedades multifuncionais, como por exemplo atividades antioxidantes e anticâncer. As características e atividades desses compostos demonstraram ser altamente dependentes da cepa e do tempo de fermentação. (Elfahri et al., 2016).

As plantas também são fontes naturais de compostos bioativos eficazes que podem ser utilizados em diversas aplicações (Bezerra et al., 2017). Nesse contexto, a flor de hibisco se destaca por apresentar diversos compostos com propriedades antioxidantes, os quais podem ser mais eficientes e menos custosos que aditivos sintéticos. O hibisco vem atraindo a atenção da indústria de alimentos pela possibilidade de aplicação desse vegetal como matéria prima para elaboração de novos produtos, podendo ser utilizado como fibra dietética e corante. Além disso, apresenta-se como uma planta com boa perspectiva por ser rica em compostos fenólicos e com alta propriedade antioxidante (Abreu et al., 2019).

Portanto, o objetivo do trabalho foi desenvolver um leite fermentado pela ação de L. helveticus associado ou não de $S$. thermophillus adicionado de extrato de hibisco livre ou encapsulado e avaliar as características físico-químicas, atividade antioxidante e viabilidade microbiana durante a estocagem sobre refrigeração. 


\section{Metodologia}

\subsection{Materiais}

Para o estudo foi utilizado leite em pó desnatado instantâneo (Molico, Nestlé), açúcar cristal (Usina Alto Alegre) constituído fundamentalmente por sacarose, cultura liofilizada de L. helveticus Lyofast LH 091 (SACCO Brasil) e de $S$. thermophilus Granoferm M450 (Granolab do Brasil S/A), ambas adquiridas comercialmente pela Somarole comercial LTDA, e flor de hibisco desidratada, obtida no mercado municipal da cidade de Campo Mourão - PR. polivinilpirrolidona (PVP, Mw = 40.000 g/mol, Sigma Aldrich) e o Tween 80 (P.A., Dinâmica) foram utilizados na encapsulação do extrato de hibisco.

\subsection{Obtenção do extrato de hibisco e encapsulação}

O extrato de hibisco livre foi extraído a partir das flores de hibiscos desidratadas adicionadas em água destilada aquecida a $80{ }^{\circ} \mathrm{C}(2 \% \mathrm{p} / \mathrm{v})$, sob homogeneização em ultra-turrax (T25, IKA) por 15 min a $10.000 \mathrm{rpm}$ com temperatura controlada, conforme a metodologia de Rasheed et al. (2018).

Para o preparo do extrato encapsulado, foram aplicadas as metodologias descritas por Rasheed et al. (2018) e Silva (2017), unindo as metodologias de extração e encapsulação. Foi homogeneizado as flores de hibiscos desidratados (2\% p/v), água destilada aquecida a $80^{\circ} \mathrm{C}$, o encapsulante PVP $(0,5 \%$ P/V) e o surfactante Tween $80(0,05 \%$ p/v). A mistura também permaneceu sob agitação em ultra-turrax (T25, IKA) por 15 min a 10.000 rpm com temperatura controlada.

Após o processo, ambas misturas foram filtradas a vácuo e os extratos livres e encapsulado obtidos foram secos em estufa de circulação a $60^{\circ} \mathrm{C}$. Após o processo, foram coletados, congelados e armazenados em freezer até o momento de aplicação.

\subsection{Rendimento dos extratos}

Para o cálculo do rendimento de extração e de extração/encapsulação, alíquotas de $5 \mathrm{~mL}$ de cada experimento, obtidas da solução após a filtração, foram colocadas em placas de Petri previamente pesadas em balança analítica. Após secagem em estufa de circulação a $60^{\circ} \mathrm{C}$ até evaporação completa da água, as placas foram pesadas novamente para determinação do teor de sólidos secos $\left(\mathrm{m}_{\mathrm{ss}}(\mathrm{g})\right)$. O cálculo do rendimento foi expresso em porcentagem e determinado através da Equação 1, onde $\mathrm{V}_{\mathrm{TS}}$ $(\mathrm{mL})$ refere-se ao volume total de solvente utilizado na extração, $\mathrm{V}_{\mathrm{a}}(\mathrm{mL})$ é o volume da alíquota utilizada para o cálculo do rendimento, $\mathrm{m}_{\mathrm{si}}(\mathrm{g}$ ) é a massa de sólidos inicial presente no processo (hibisco no caso da extração; hibisco, PVP e Tween 80 no caso da extração/encapsulação).

Rendimento $(\%)=\frac{m_{s S} \times V_{T S}}{V_{a} \times m_{s i}} \times 100$

\subsection{Elaboração do leite fermentado}

Os leites fermentados foram elaborados conforme o fluxograma apresentado na Figura 1. Inicialmente, foi preparado uma base com leite em pó desnatado reconstituído (14\% de sólidos totais) e adição de $7 \%$ de sacarose; homogeneizados com água destilada até atingir a completa diluição. A base foi tratada termicamente a $90{ }^{\circ} \mathrm{C}$ por 5 minutos. 
Figura 1 - Fluxograma de fabricação dos leites fermentados.

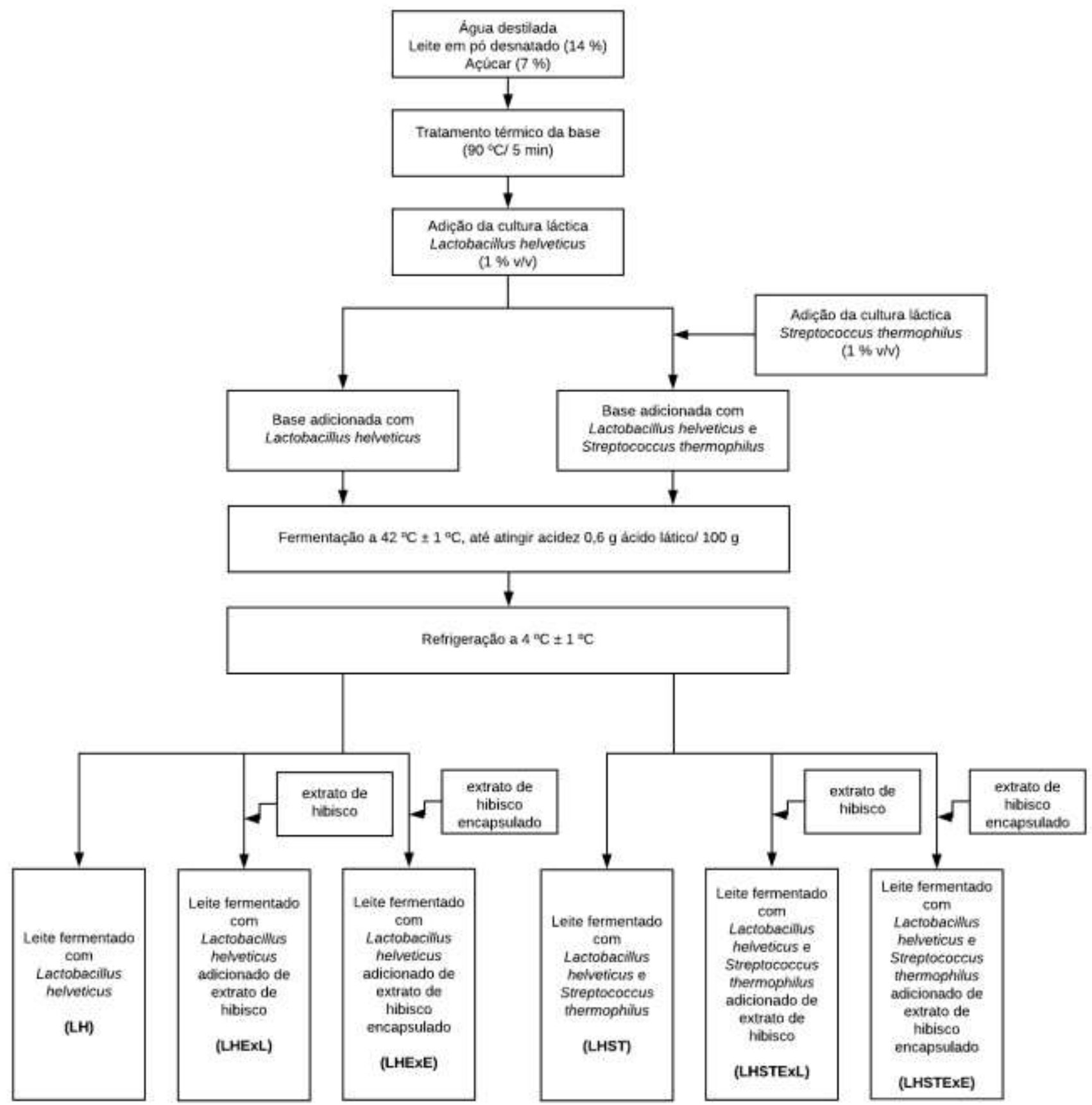

Fonte: Autores (2021).

A base foi acondicionada em dois frascos com tampa, previamente esterilizados, e resfriadas até a temperatura de 42 ${ }^{\circ} \mathrm{C}$. Cada uma recebeu diferentes fermentos láticos (tratamentos): L. helveticus (1\% v/v) (LH), e a outra adicionada com $S$. thermophilus (1\% v/v) e L. helveticus (1\% v/v) (LHST); as concentrações foram adicionadas conforme a recomendação do fabricante para volume da base processada. Os frascos foram colocados na estufa a $42{ }^{\circ} \mathrm{C}$; e em intervalos de 1 hora foi realizado o acompanhamento da acidez titulável de amostras em paralelo. O processo de fermentação foi interrompido quando o leite fermentado atingiu 0,6 gramas de ácido láctico por 100 gramas, limite mínimo exigido pelo Regulamento Técnico de Identidade e Qualidade de Leites Fermentados (Brasil, 2007). 
Após a fermentação, os leites fermentados foram resfriados até $\left(4 \pm 1{ }^{\circ} \mathrm{C}\right)$ e mantidas por um período de 12 horas de armazenamento. Cada tratamento foi subdividido em: leite fermentado sem adição (LH ou LHST), leite fermentado adicionado da solução de extrato de hibisco livre (LHExL ou LHSTExL) e o terceiro adicionado da solução de extrato de hibisco encapsulado (LHExE ou LHSTExE). Para a adição nos leites fermentados, tanto o extrato encapsulado quanto o extrato de hibisco foram previamente solubilizados em água destilada a $0,2 \mathrm{~g} / \mathrm{mL}$ e $0,14 \mathrm{~g} / \mathrm{mL}$ respectivamente (considerando o mesmo teor de extrato para os dois tratamentos). A concentração de extrato de hibisco foi previamente calculada visando obter leites fermentados com 45 mg/100g. No Regulamento técnico sobre ingestão diária recomendada para proteínas, vitaminas e minerais (Brasil, 2005) não apresenta recomendação diária para hibisco como fonte de antioxidante, por isso, a quantidade adicionada foi conforme o valor recomendado de ingestão de vitamina $\mathrm{C}$ para adultos.

Os tratamentos foram acondicionados em frascos de $50 \mathrm{~mL}$ e armazenados a $4 \pm 1{ }^{\circ} \mathrm{C}$ por um período de 30 dias.

\subsection{Caracterização físico-química e contagem das bactérias ácido láticas}

Os leites fermentados (LH e LHST) recém elaborados foram caracterizados quanto à composição proximal. Foram realizadas análise de acidez titulável, extrato seco total, cinzas, proteínas e lipídeos segundo os procedimentos descritos por AOAC (2003). Todas as análises foram realizadas em triplicata.

A análise de contagem dos microrganismos seguiu a metodologia de Freixo (2011) com algumas modificações. Para determinação das bactérias viáveis dos leites fermentados foram utilizados meios seletivos para cada microrganismo adicionado. Na contagem do L. helveticus foi utilizado o meio MRS e para o $S$. thermophilus, o meio M17. Todo o material utilizado para a análise foi previamente esterilizado em autoclave, e as análises realizadas em câmara de fluxo laminar.

Para o preparo das amostras, foram diluídos $25 \mathrm{~mL}$ do leite fermentado em $225 \mathrm{~mL}$ de solução salina a $0,85 \%$. Diluições seriadas foram realizadas e uma alíquota de $1 \mathrm{~mL}$ de cada diluição selecionada foi inoculada em profundidade no meio adequado. As placas foram incubadas em jarras contendo gerador de anaerobiose (PROBAC - Anaerobac) a $37^{\circ} \mathrm{C}$ por 72 horas. A análise foi realizada no dia 1 e 30 dias de armazenamento.

\subsection{Determinação de atividade antioxidante por DPPH}

No período de 1,15 e 30 dias de estocagem $\left(4^{\circ} \mathrm{C}\right)$ foi avaliada a capacidade antioxidantes dos leites fermentados com ambas as BALs adicionados de extrato de hibisco (livre ou encapsulado) utilizando o método de captura do radical livre DPPH (2,2-diphenyl-1-picrylhydrazyl) conforme o procedimento de Pires et al. (2017) com algumas modificações. As amostras foram preparadas em duplicatas, sendo realizada soluções com uma alíquota de $20 \mu \mathrm{L}$ do leite fermentado diluído em $280 \mu \mathrm{L}$ de solução de DPPH (32 $\mu \mathrm{g} / \mathrm{mL})$, incubadas por 20 minutos na ausência de luz e centrifugadas por 10 minutos. Para a determinação, foram colocados os $300 \mu \mathrm{L}$ do sobrenadante em microplaca e realizada a leitura da absorbância em comprimento de onda $517 \mathrm{~nm}$ em espectrofotômetro. A capacidade sequestro de radicais livres (\%) foi calculada pela Equação 2.

$\% A A O=\frac{(\text { Abs Controle DPPH }- \text { Abs Amostra }) \times 100}{\text { Abs Controle DPPH }}$

\subsection{Método de Redução do Íon Férrico (FRAP)}

No período de 1,15 e 30 dias de estocagem $\left(4^{\circ} \mathrm{C}\right)$ foi realizada a análise identificação dos compostos redutores de íons de ferro conforme descrito por Urrea-Victoria et al. (2016) com algumas modificações de ambas as BALs adicionados de extrato de hibisco (livre ou encapsulado). As amostras foram preparadas em triplicata, sendo inicialmente preparado a solução do complexo férrico pela adição $5 \mathrm{~mL}$ da solução TPTZ $10 \mathrm{Mm}, 5 \mathrm{~mL}$ da solução de cloreto férrico $20 \mathrm{mM}$ e $50 \mathrm{~mL}$ de tampão de acetato de sódio 0,3 M. O preparo do meio reacional foi realizado pela adição de $3000 \mu \mathrm{L}, 370 \mu \mathrm{L}$ de água destilada e $100 \mu \mathrm{L}$ 
de amostra. O branco foi preparado com a adição de $3000 \mu \mathrm{L}$ e $470 \mu \mathrm{L}$ de água destilada. Em seguida, os tubos foram colocados em banho-maria a $37^{\circ} \mathrm{C}$ por 30 minutos. Por fim, foi realizado a leitura da absorbância em espectrofotômetro 595 nm. O potencial antioxidante de FRAP foram expressos como mmol equivalente de trolox por litro $\left(y=0,0012 \cdot x+0,0008 ; R^{2}=0,997\right)$.

\subsection{Análise Estatística}

Todos os resultados foram submetidos à ANOVA e as médias da composição proximal e viabilidade microbiológica foram submetidos ao teste t-Student $(\mathrm{p}<0,05)$, enquanto os dados de atividades antioxidantes foram comparados pelo teste de Tukey no nível de 5\% de significância. O tratamento dos dados foi efetuado no software Statistica 7.0 (Statsoft, EUA).

\section{Resultados e Discussão}

\subsection{Rendimentos dos Extratos}

Após o processo de secagem foi possível determinar os rendimentos dos extratos. Estatisticamente, os rendimentos apresentaram diferença significativa, que pode ser justificada pela adição do PVP e do TWEEN 80 para obtenção do extrato de hibisco encapsulado. Os resultados dos rendimentos foram satisfatórios, apresentando valores médio de $60,95 \% \pm 3,75$ para o extrato de hibisco livre e $67,15 \% \pm 3,87$ para o extrato de hibisco encapsulado.

Jung \& Joo (2013) em seu estudo sobre os efeitos do hibisco e do óleo de soja nas características de qualidade de hambúrguer de porco, determinou um rendimento de $38 \%$ para extratos aquosos de cálices de hibisco. É possível que o valor de rendimento determinado pelo autor tenha sido menor do que o do presente trabalho em função da aplicação dos parâmetros de agitação e da temperatura diferentes aos adotados no processo de extração realizado neste estudo.

\subsection{Caracterização Físico-Química e Microbiológicas dos Leites Fermentados} Tabela 1.

Os resultados da análise de composição centesimal, bem como a contagem de microrganismos são demonstrados na

Tabela 1 - Composição centesimal dos leites fermentados por L. helveticus (LH) e L. helveticus e S. thermophilus (LHST) após a fermentação e contagem das culturas láticas no tempo 1 e 30 dias estocadas a temperatura $4 \pm 1^{\circ} \mathrm{C}$.

\begin{tabular}{lcc}
\hline & \multicolumn{2}{c}{ Leites fermentados } \\
\cline { 2 - 3 } & \multicolumn{1}{c}{ S. thermophilus e L. helveticus (LHST) } & L. helveticus (LH) \\
\hline Umidade (\%) & \multicolumn{1}{c}{ Análises Físico-químicas } \\
\hline Cinzas (\%) & $1,18^{\mathrm{a}} \pm 0,05$ & $79,94^{\mathrm{a}} \pm 0,57$ \\
\hline Proteína (\%) & $1,89^{\mathrm{b}} \pm 0,03$ & $1,03^{\mathrm{a}} \pm 0,24$ \\
\hline Lipídeos (\%) & $0,00^{\mathrm{a}} \pm 0,00$ & $3,51^{\mathrm{a}} \pm 0,06$ \\
\hline Carboidratos (\%) & $16,60^{\mathrm{a}} \pm 1,23$ & $0,00^{\mathrm{a}} \pm 0,00$ \\
\hline Acidez titulável & $1,11^{\mathrm{a}} \pm 0,07$ & $15,52^{\mathrm{a}} \pm 0,55$ \\
\hline$\%$ g. de ácido lático/100 g) & & $0,80^{\mathrm{b}} \pm 0,02$ \\
\hline & Análises Microbiológicas \\
\hline Dia 1 & Contagem total das bactérias ácido láticas (UFC/g) \\
\hline Dia 30 & $9,77 \times 10^{9}$ Aa & $1,65 \times 10^{8 \mathrm{Ab}}$ \\
\hline
\end{tabular}

\footnotetext{
${ }^{\mathrm{a}, \mathrm{b}}$ Médias seguidas de letras minúsculas diferentes na mesma linha indicam diferença significativa entre os tratamentos pelo teste $\mathrm{t}$-Student $(\mathrm{p}<0,05)$.

A,B Médias na mesma coluna seguidas por letras maiúsculas iguais não diferem estatisticamente entre si, pelo teste $t-$ Student $(p<0,05)$, ao longo do tempo de armazenamento. Fonte: Autores (2021).
} 
O teor de umidade e cinzas não são estabelecidas recomendações mínimas pela legislação (Brasil, 2007), entretanto, é possível observar que os valores obtidos para ambas as formulações foram estatisticamente iguais. Os valores para ambos os parâmetros foram próximos ao encontrado por Vanegas-Azuero \& Gutiérrez (2018) na formulação do iogurte controle preparado com leite em pó desnatado reconstituído a 13\% (p/p) em água destilada.

Para ambas as formulações a base inicial foi a mesma, entretanto o teor de proteína da formulação $S$. thermophilus e $L$. helveticus apresentou este valor inferior ao leite fermentado somente por $L$. helveticus $(\mathrm{p}<0,05)$. Aparentemente houve problemas de homogeneização de componentes do leite em pó entre as formulações ou atividades metabólicas das cepas $S$. thermophilus ao longo da fermentação.

O regulamento técnico do MAPA estabelece que os leites fermentados devem apresentar teor proteico de no mínimo 2,9\%, com exceção de leites fermentados com agregados, açucarados e/ou saborizados, sendo assim somente o leite fermentado por L. helveticus atendeu ao padrão estabelecido pela legislação.

Em relação à composição de lipídeos, o teor apresentado permite classificar as formulações como leite fermentado desnatado. O seu baixo teor deve-se à utilização de apenas leite em pó desnatado para preparação dos fermentados.

A amostra de leite fermentado com a cultura isolada de L. helveticus apresentou teor de carboidratos de $15,52 \% \pm 0,55$ e a amostra adicionada da co-cultura S. thermophilus, teor de $16,60 \% \pm 1,23$; valores elevados eram esperados e justificados pela adição de sacarose na formulação.

A acidez titulável do leite fermentado pelas duas cepas apresentou significativamente superior comparado ao somente fermentado por L. helveticus. Antigo et al. (2020) desenvolveu iogurte fermentado por Lactobacillus acidophilus, Bifidobacterium animalis subsp. lactis e S. thermophilus adicionado de corante de beterraba apresentou acidez médio de $0,8 \%$ de ácido lático/100 g.

O leite fermentado por $L$. helveticus e S. thermophilus apresentaram contagem superior ao fermentado somente por $L$. helveticus. Por outro lado, esta última formulação apresentou estável ao longo dos 30 dias de estocagem, mantendo sua contagem ( $>0,05)$. Entretanto, durante o armazenamento refrigerado, ambas amostras do leite fermentado apresentaram contagem superiores a $10^{7} \mathrm{UFC} / \mathrm{g}$, contagem mínima estabelecida pela legislação (Brasil, 2007).

\subsection{Atividade antioxidante por DPPH}

A substância com potencial antioxidante é capaz de doar um átomo de hidrogênio para reduzir o radical DPPH a DPPHH, produzindo um decréscimo da absorbância a 515/517nm (Pires et al., 2017). O potencial pode ser expresso em porcentagem de atividade antioxidante. Desta forma, de acordo com os valores apresentados na Tabela 2, as porcentagens da atividade de eliminação dos radicais DPPH dos leites fermentados foram maiores que $70,91 \%$. 
Tabela 2 - Capacidade de inibição do radical DPPH (expresso em \% de inibição) pelos leites fermentados por L. helveticus (LH) e L. helveticus e S. thermophilus (LHST), leite fermentado adicionado da solução de extrato de hibisco livre (LHExL ou LHSTExL) ou adicionado da solução de extrato de hibisco encapsulado (LHExE ou LHSTExE) ao longo de 30 dias de estocagem a $4 \pm 1^{\circ} \mathrm{C}$.

\begin{tabular}{lccc}
\hline \multirow{2}{*}{ LEITES FERMENTADOS } & \multicolumn{3}{c}{$\%$ de inibição do radical DPPH } \\
\cline { 2 - 4 } LH & 1 dia & 15 dias & 30 dias \\
\hline LHExL & $97,37^{\mathrm{Aa}} \pm 1,97$ & $90,30^{\mathrm{Aa}} \pm 2,96$ & $70,91^{\mathrm{Ab}} \pm 0,48$ \\
\hline LHExE & $81,27^{\mathrm{Abc}} \pm 0,66$ & $82,62^{\mathrm{Ab}} \pm 0,70$ & $79,05^{\mathrm{Aa}} \pm 0,59$ \\
\hline LHST & $93,65^{\mathrm{Aa}} \pm 1,09$ & $97,19^{\mathrm{Aa}} \pm 0,11$ & $86,50^{\mathrm{Aa}} \pm 12,21$ \\
\hline LHSTExL & $81,73^{\mathrm{Aac}} \pm 22,99$ & $92,70^{\mathrm{Aa}} \pm 8,93$ & $83,95^{\mathrm{Aa}} \pm 19,36$ \\
\hline LHSTExE & $92,88^{\mathrm{Aa}} \pm 1,31$ & $91,14^{\mathrm{Aa}} \pm 7,69$ & $81,06^{\mathrm{Aa}} \pm 8,07$ \\
\hline
\end{tabular}

a,b Médias na mesma coluna seguidas por letras minúsculas iguais não diferem estatisticamente entre si, pelo teste Tukey ( $\mathrm{p}>0,05)$, para o mesmo período de armazenamento.

${ }_{\mathrm{A}, \mathrm{B}}$ Médias na mesma linha seguidas por letras maiúsculas iguais não diferem estatisticamente entre si, pelo teste Tukey ( $\left.\mathrm{p}>0,05\right)$, ao longo do tempo de armazenamento. Fonte: Autores (2021).

Valores próximos foram encontrados no estudo de Namdari \& Nejati (2016) que avaliou a capacidade de isolados de $L$. helveticus durante a fermentação e o armazenamento de leite fermentados. Não foi possível concluir o efeito da associação das culturas láticas e adição do extrato de hibisco em ambas as formas sobre a atividade antioxidante do leite fermentado no tempo inicial. Por outro lado, não houve redução da atividade antioxidante ao longo do tempo de armazenamento para todos os tratamentos e aos 30 dias todos os tratamentos apresentaram valores estatisticamente iguais neste parâmetro estudado ( $\mathrm{p}>0,05$ ).

A atividade antioxidante dos leites fermentados exibiu valores expressivos, entretanto, a adição dos extratos de hibisco não proporcionou aumento da atividade antioxidante, de forma que as amostras resultaram em valores estatisticamente iguais. Esses resultados indicam que a capacidade antioxidante dos extratos de hibisco pode ter sido afetada pelas interações entre as proteínas do leite e os polifenóis, como relatado no estudo de Xiao et al. (2011), demonstrando que a interação das proteínas do leite enfraqueceu significativamente o potencial de eliminação do radical livres DPPH dos polifenóis.

Pode-se concluir que a atividade antioxidante dos leites fermentados foi resultado derivado exclusivamente da alta atividade proteolítica do L. helveticus, produzindo peptídeos bioativos com capacidade antioxidante. No trabalho sobre o potencial de cepas de Lactobacillus para controle da oxidação de lipídeos e proteínas em iogurtes foi observado que dentre as cepas estudadas o L. helveticus apresentou a maior atividade sequestrante de radicais e maior estabilidade oxidativa durante o armazenamento refrigerado. Sugerindo que ocorre o aumento da atividade antioxidante conforme a viabilidade das cepas e do processo fermentativo, podendo ser resultado da lise celular, peptídeos proteicos e metabólitos extracelulares (Hashemi et al., 2021).

\subsection{Método de Redução do Íon Férrico (FRAP)}

O ensaio antioxidante de determinação do poder de redução do íon ferro, FRAP (do inglês Ferric Reducing Antioxidant Power), é baseado na produção do íon $\mathrm{Fe}^{2+}$ (forma ferrosa) a partir da redução do íon $\mathrm{Fe}^{3+}$ (forma férrica) presente no complexo 2,4 (Urrea-Victoria et al., 2016). Assim, conforme se observa com os dados da Tabela 3, a fermentação com L. helveticus apresentou efeito positivo na capacidade antioxidante de todos os leites fermentados. 
Tabela 3 - Resultados da análise de atividade antioxidante pelo método FRAP (expresso em capacidade antioxidante Trolox equivalente) de leites fermentados por L. helveticus (LH) e L. helveticus e S. thermophilus (LHST), leite fermentado adicionado da solução de extrato de hibisco livre (LHExL ou LHSTExL) ou adicionado da solução de extrato de hibisco encapsulado (LHExE ou LHSTExE) ao longo de 30 dias de estocagem a $4 \pm 1^{\circ} \mathrm{C}$.

\begin{tabular}{lccc}
\hline \multirow{2}{*}{ LEITES FERMENTADOS } & \multicolumn{3}{c}{ FRAP $(\mathrm{mmol}$ Trolox/L) } \\
\cline { 2 - 4 } LH & $1 \mathrm{dia}$ & 15 dias & 30 dias \\
\hline LHExL & $0,85^{\mathrm{Ab}} \pm 0,00$ & $0,82^{\mathrm{ABa}} \pm 0,01$ & $0,80^{\mathrm{Bab}} \pm 0,02$ \\
\hline LHExE & $0,79^{\mathrm{Bb}} \pm 0,05$ & $0,85^{\mathrm{ABa}} \pm 0,04$ & $0,94^{\mathrm{Aab}} \pm 0,06$ \\
\hline LHST & $1,04^{\mathrm{Aa}} \pm 0,05$ & $0,88^{\mathrm{Ba}} \pm 0,03$ & $0,98^{\mathrm{ABa}} \pm 0,06$ \\
\hline LHSTExL & $0,67^{\mathrm{Ac}} \pm 0,01$ & $0,76^{\mathrm{Aa}} \pm 0,08$ & $0,77^{\mathrm{Ab}} \pm 0,13$ \\
\hline LHSTExE & $0,79^{\mathrm{Ab}} \pm 0,02$ & $0,79^{\mathrm{Aa}} \pm 0,06$ & $0,83^{\mathrm{Aab}} \pm 0,04$ \\
\hline
\end{tabular}

a,bMédias na mesma coluna seguidas por letras minúsculas iguais não diferem estatisticamente entre si, pelo teste Tukey ( $\mathrm{p}>0,05$ ), para o mesmo período de armazenamento.

A,BMédias na mesma linha seguidas por letras maiúsculas iguais não diferem estatisticamente entre si, pelo teste Tukey (p>0,05), ao longo do tempo de armazenamento. Fonte: Autores (2021).

Os dados também demonstram que a amostra LHExE, no dia 1, apresentou maior poder redutor, com valor médio de 1,04 \pm 0,05 mmol Trolox/L, enquanto a amostra LHST apresentou menor atividade $(\mathrm{p}<0,05)$, com valor médio de $0,67 \pm 0,01$ mmol Trolox/L. Os resultados neste estudo permitiram observar que, o LH associado ao extrato de hibisco encapsulado (LHExE) parece ter contribuído com maior atividade antioxidante. Enquanto o leite fermentado LHST, embora tenha apresentado menor atividade, a associação com o extrato de hibisco parece incrementar sua capacidade antioxidante.

Houve efeito da estocagem sobre a atividade antioxidante do leite fermentado LH e LHSTExE, onde o LH reduziu significativamente a capacidade antioxidante, enquanto o segundo houve aumento. A aplicação de extrato de hibisco contribuiu com a estabilidade da atividade antioxidante comparado ao leite fermentado sem sua adição.

O estudo El-Sayed et al. (2021) demonstrou resultado semelhante, sendo o leite fermentado pela cultura do L. helveticus a amostra que apresentou maior grau de proteólise e maiores valores de FRAP quando comparado com cultura comercial e com cepas únicas de lactobacillus, onde o autor concluiu uma possível correlação direta da atividade proteolítica com a capacidade antioxidante, devido a produção de peptídeos bioativos.

Observou-se também que o leites fermentados com e sem adição dos extratos exibiram valores semelhantes estatisticamente, assim como encontrado no estudo de Gasparin (2015) ao realizar o método de FRAP para queijo minas curado com e sem adição de cúrcuma, determinando que não houve diferença entre o controle e os tratamentos. Segundo Kabir et al., (2021), esse resultado pode ser explicado devido a possível interação das proteínas do leite com compostos fenólicos. Sendo assim, a atividade antioxidante das antocianinas, principais compostos fenólicos do extrato de hibisco, pode ser mascarada por interações com proteínas do leite.

\section{Conclusão}

Ao avaliar a composição o leite fermentado por LHST apresentou teor de proteína significativamente inferior ao LH. Por outro lado, a acidez titulável do LH foi menor comparado ao LHST. Quanto a contagem microbiológica, o leite fermentado LHST apresentou contagem de bactérias ácido láticas totais superior ao LH, embora ambos atendam aos limites legais ao longo do tempo de estocagem sob refrigeração.

Não houve efeito significativo relativo a atividade antioxidante determinado pelo DPPH no tempo inicial, porém os valores se mantiveram estáveis ao longo do tempo de armazenamento. 
Inicialmente o LH apresentou maior atividade antioxidante pelo FRAP quando associado ao extrato de hibisco encapsulado. A associação do extrato de hibisco seja na forma encapsulada ou livre contribuíram com a estabilidade da capacidade antioxidante ao longo do tempo de estocagem.

Os resultados permitem concluir que o leite fermentado por L. helveticus apresentou melhor atividade antioxidante determinado pelo método FRAP quando associado ao extrato de hibisco, independente da forma adicionada ao produto.

\section{Referências}

ABREU, Bruna Barbosa et al. (2019). Composição centesimal, compostos bioativos e atividade antioxidante em cálice de hibisco (Hibiscus sabdariffa L.). Journal Interdisciplinar de Biociências, [s. 1.], 4 (1), p. 1.

Antigo, J. L. D.; Silva, J. M.; Bergamasco, R. C.; Madrona, G. S. (2020). Microencapsulation of beet dye (Beta vulgaris L.) using maltodextrin and xanthan gum as encapsulant agents and application in yogurt. Research, Society and Development, 9(12), e14091210896. https://doi.org/10.33448/rsd-v9i12.10896.

Bezerra, A. S., Stankievicz, S. A., Kaufmann, A. I., Machado, A. A. R., \& Uczay, J. (2017). Composição nutricional e atividade antioxidante de plantas alimentícias não convencionais da região sul do Brasil. Arquivos Brasileiros de Alimentação, 2(3), p. 182-188.

Borgonovi, T. F. (2018). Biocompostos das polpas de maracujá e de buriti: caracterização e aplicação em leite [Dissertação (Mestrado)]. Universidade Estadual Paulista "Júlio de Mesquita Filho", Instituto de Biociências, Letras e Ciências Exatas.

Brasil. Ministério da Agricultura, Pecuária e Abastecimento. Instrução normativa n.46 (2007). Aprova o Regulamento Técnico de Identidade e Qualidade de Leites Fermentados. Diário Oficial da União, Seção 1, p. 4.

Brasil. Ministério da Saúde. Resolução RDC n. 269 (2005). Regulamento Técnico sobre ingestão diária recomendada (IDR) de proteína, vitaminas e minerais. Diário Oficial da União, Brasília.

Capitani, C., Hauschild, F. A. D., Friedrich, C. J., Lehn, D. N., \& Souza, C. F. V. de. (2014). Caracterização de iogurtes elaborados com probióticos e fibra solúvel. Revista Brasileira de Tecnologia Agroindustrial, 08(02), p. 1285-1300. https://doi.org/10.3895/S1981-3686201400020 0001

El-Sayed, M. I., Awad, S., \& Abou-Soliman, N. H. I. (2021). Improving the Antioxidant Properties of Fermented Camel Milk Using Some Strains of Lactobacillus. Food and Nutrition Sciences, 12, p. 352-371. https://doi.org/10.4236/fns.2021.124028

Elfahri, K. R., Vasiljevic, T., Yeager, T., \& Donkor, O. N. (2016). Anti-colon cancer and antioxidant activities of bovine skim milk fermented by selected Lactobacillus helveticus strains. Journal of Dairy Science, 99(1), p. 31-40. https://doi.org/10.3168/jds.2015-10160

Gasparin, K. (2015). Desenvolvimento de queijo minas curado com adição de Enterococcus faecium EF 1, Lactobacillus helveticus LH 13 e extrato de cúrcuma (Curcuma longa L.) [Dissertação (Mestrado)]. Universidade Estadual de Londrina, Centro de Ciências Agrárias.

Gösta Bylund, M. S. (2015). Dairy processing handbook (3º ed). Tetra Pak Processing Systems AB.

Hashemi, S. M. B., Gholamhosseinpour, A., \& Abedi, E. (2021). Biopreservative potential of Lactobacillus strains in yoghurt dessert. Journal of Food Measurement and Characterization, 15, p. 1634-1643. https://doi.org/10.1007/s11694-020-00755-z

Instituto Adolfo Lutz. (2004). Métodos Físico-Químicos para Análise de Alimentos (4ºd). São Paulo: Instituto Adolfo Lutz, 1020 p.

Jung, E., \& Joo, N. (2013). Roselle (Hibiscus sabdariffa 1.) and soybean oil effects on quality characteristics of pork patties studied by response surface methodology. Meat Science, 94, p. 391-401. https://doi.org/10.1016/j.meatsci.2013.02.008

Kabir, M. R., Hasan, M. M., Islam, M. R., Haque, A. R., \& Hasan, S. M. K. (2021). Formulation of yogurt with banana peel extracts to enhance storability and bioactive properties. Journal of Food Processing and Preservation, 45, p. 1-10. https://doi.org/10.1111/jfpp.15191

Namdari, A., \& Nejati, F. (2016). Development of antioxidant activity during milk fermentation by wild isolates of Lactobacillus helveticus. Applied Food Biotechnology, 3(3), p. 178-186.

Pires, J., Torres, P. B., Santos, D. Y. A. C. dos, \& Chow, F. (2017). Ensaio em microplaca do potencial antioxidante através do método de sequestro do radical livre DPPH para extratos de algas. Instituto de Biociências, Universidade de São Paulo, p. 6.

Rasheed, D. M., Porzel, A., Frolov, A., El Seedi, H. R., Wessjohann, L. A., \& Farag, M. A. (2018). Comparative analysis of Hibiscus sabdariffa (roselle) hot and cold extracts in respect to their potential for $\alpha$-glucosidase inhibition. Food Chemistry, 250, p. 236-244. https://doi.org/10.1016/j.foodchem.2018.01.020

Sah, B. N. P., Vasiljevic, T., McKechnie, S., \& Donkor, O. N. (2014). Effect of probiotics on antioxidant and antimutagenic activities of crude peptide extract from yogurt. Food Chemistry, 156, p. 264-270. https://doi.org/10.1016/j.foodchem.2014.01.105

Silva, A. B. da, Wiest, J. M., \& Carvalho, H. H. C. (2016). Compostos químicos e atividade antioxidante analisados em Hibiscus rosa-sinensis L. (mimo-devênus ) e Hibiscus syriacus L. (hibisco-da-síria). Brazilian Journal of Food Technology, 19, p.1-9. https://doi.org/10.1590/1981-6723.7415

Tamime, A. (2006). Fermented Milk. (1. ed). Oxford: Blackwell Science Ltda, 262 p.

Urrea-Victoria, V., Pires, J., Torres, P. B., Santos, D. Y. A. C. dos, \& Chow, F. (2016). Ensaio antioxidante em microplaca do poder de redução do ferro ( FRAP) 
Research, Society and Development, v. 11, n. 1, e18211124475, 2022

(CC BY 4.0) | ISSN 2525-3409 | DOI: http://dx.doi.org/10.33448/rsd-v11i1.24475

para extratos de algas. Instituto de Biociências, Universidade de São Paulo, p. 1-6.

Vanegas-Azuero, A. M., \& Gutiérrez, L. F. (2018). Physicochemical and sensory properties of yogurts containing sacha inchi (Plukenetia volubilis L.) seeds and $\beta$-glucans from Ganoderma lucidum. Journal of Dairy Science, 101, p. 1020-1033. https://doi.org/10.3168/jds.2017-13235

Xiao, J., Mao, F., Yang, F., Zhao, Y., Zhang, C., \& Yamamoto, K. (2011). Interaction of dietary polyphenols with bovine milk proteins: Molecular structureaffinity relationship and influencing bioactivity aspects. Molecular Nutrition and Food Research, 55, p. 1637-1645. https://doi.org/10.1002/mnfr.201100280 